\title{
Correction to: Can high-performance funds be built and managed by improving their network locations? -- evidence from entrepreneurship in Chinese fund managers
}

\author{
Xiaoying Zhai ${ }^{1} \cdot$ Huiping Ma ${ }^{1} \cdot{\text { Yongmin } Z^{2}}$ Yng $^{2}$ \\ Published online: 19 February 2022 \\ ๑) Springer Science+Business Media, LLC, part of Springer Nature 2022
}

\section{Correction to: International Entrepreneurship and Management Journal https://doi.org/10.1007/s11365-021-00779-x}

The original article has been corrected. The correct author affiliation should be:

${ }^{1}$ School of Economics and Management, Shanxi, Shanxi University

${ }^{2}$ School of Business and Research Academy of Belt \& Road, Ningbo, Ningbo University

Publisher's Note Springer Nature remains neutral with regard to jurisdictional claims in published maps and institutional affiliations.

The original article can be found online at https://doi.org/10.1007/s11365-021-00779-x.

\section{Yongmin Zhang}

zhangyongmin@nbu.edu.cn

1 School of Economics and Management, Shanxi University, Shanxi, China

2 School of Business and Research Academy of Belt \& Road, Ningbo University, Ningbo, China 